\title{
Mitral incompetence after repair of ostium primum septal defects
}

\author{
A.R. C. DOBELL, D.R. MURPHY, G . M . KARN, \\ AND A. MARTINEZ-CARO
}

From the Department of Cardiovascular Surgery, the Montreal Children's Hospital, Montreal, Quebec, Canada

Experience in the surgical treatment of endocardial cushion defects has been reported by a number of authors (Cooley, Kirklin, and Harshbarger, 1957 ; McGoon, DuShane, and Kirklin, 1959; Crafoord and Senning, 1960; Dubost and Blondeau, 1960; Ellis, McGoon, and Kirklin, 1960 ; Gerbode, Johnston, Robinson, Harkins, and Osborn, 1961 ; Maloney, Marable, and Mulder, 1962 ; Scott, Hauck, Nadas, and Gross, 1962). These papers have focused attention on the technical details of surgical repair, and for the most part they have taken survival as their standard of a successful operative repair. In evaluating the experience at the Montreal Children's Hospital, we became aware that degrees of correction are possible, and with this in mind the results in the 27 patients with endocardial cushion defects who have been surgically treated were critically reviewed. Eighteen of these had an ostium primum atrial septal defect without an interventricular communication and they form the basis of this report.

The 18 patients were operated upon from five years to four months ago. At the time of operation there was a complete cleft of the aortic leaflet of the mitral valve in 15 patients, a partial cleft in one patient, and in two patients no cleft was found. One patient had no atrial septum whatsoever, there being a single common atrial chamber into which drained two superior venae cavae, the inferior vena cava, and the four pulmonary veins. In another patient, the mitral valve was unusual in that there was central fusion between the aortic and the mural leaflets, producing a bridge of valve tissue extending between the two leaflets. These abnormalities are shown in Figure 1 . In the surgical repair the mitral valve cleft was closed with interrupted sutures. The mitral insufficiency was then tested and if further sutures appeared indicated, they were added. Abnormal chordae inserting directly into the ventricular septum were searched for but were not recognized despite our realization that they are often present as reported by Edwards (1960). The upper part of the ventricular septum immediately below the atrioventricular valves was probed in order to determine whether a small ventricular septal defect might be present. The low atrial septal defect was closed in all but one of the patients with a patch of teflon felt sutured in place with multiple peripheral sutures. Inferiorly, the patch was sutured to valve tissue.

All 18 patients survived operation. With the exception of the last patient, who was operated upon too recently for evaluation, they have been evaluated up to four years post-operatively, with particular attention to the degree of mitral insufficiency. The children and their parents have been questioned with regard to symptoms. They have all undergone competent physical examination, and the presence and intensity of an apical pansystolic murmur have been recorded. In many cases, phonocardiograms have been taken. Excessive activity of the left ventricle has been noted. Radiographs have been taken in two planes to detect any change in heart size, as compared to the pre-operative radiograph, as well as any possible dilatation of the left atrium since the partitioning of the atrial septum. As a result of these examinations of the 17 patients, eight are now classified as having no mitral insufficiency (Table I). In a further seven patients mitral insufficiency is present but is clinically insignifi-

\section{TAB L E I}

PARTIAL ENDOCARDIAL CUSHION DEFFCT: POSTOPERATIVE RESULTS IN 17 PATIENTS

\begin{tabular}{llllll|c}
\hline \multicolumn{3}{c|}{ Mitral Insufficiency } & $\begin{array}{c}\text { No. of } \\
\text { Patients }\end{array}$ \\
\hline None & & & & \\
Clinically insignificant & $\ldots$ & $\ldots$ & $\ldots$ & $\ldots$ & $\mathbf{8}$ \\
Significant & $\ldots$ & $\ldots$ & $\ldots$ & $\ldots$ & $\ldots$ & $\mathbf{7}$ \\
\hline
\end{tabular}




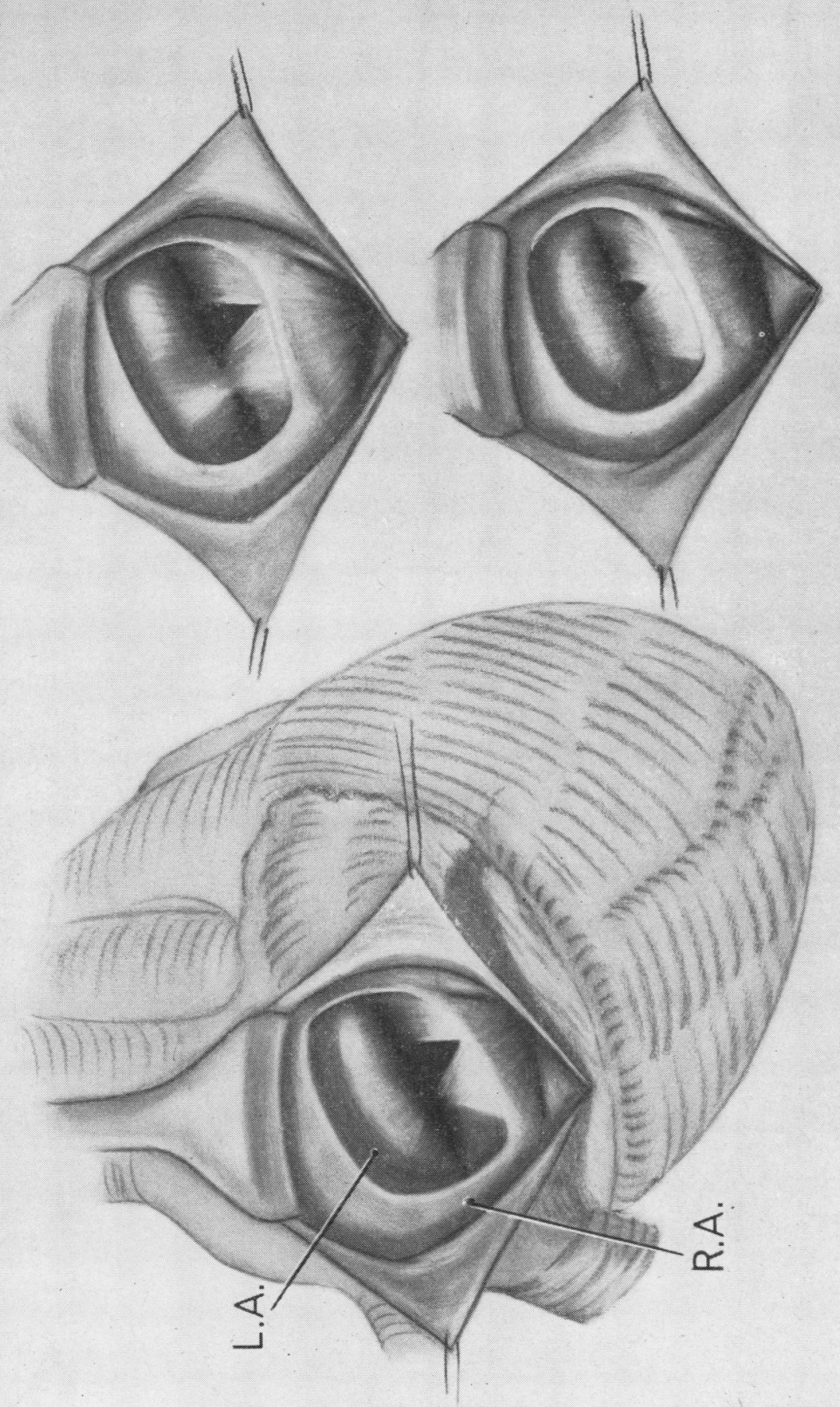

วิ

5

ฟิ

ธิ

衰哭

के

$\approx$ so

5

ธิ :

कै

政

\&

돈

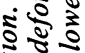

ำ $\frac{2}{2}$

ชิ

85.

ธ ฐ

บㅇำ

ํํำ

웡

के

ธิ

8

ำ

क्ष

ฮิ ปิ

ธิ

ริำ

ละ

ำำ

อัป

5.

ธั5

원

\%

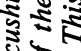

वे०

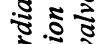

รูำ

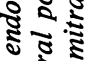

ฮี ะั

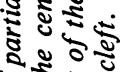

궁

$\stackrel{x}{\vec{*}}$

窎

음

음

क

$\vec{\circ}$

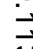

心

穴

กิ

ㅇ.

मे

옥

$\rightarrow$

ฏ)

సั

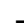

呑

뭉 ประ

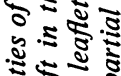
ปัป

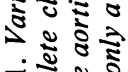

ن 
(a)
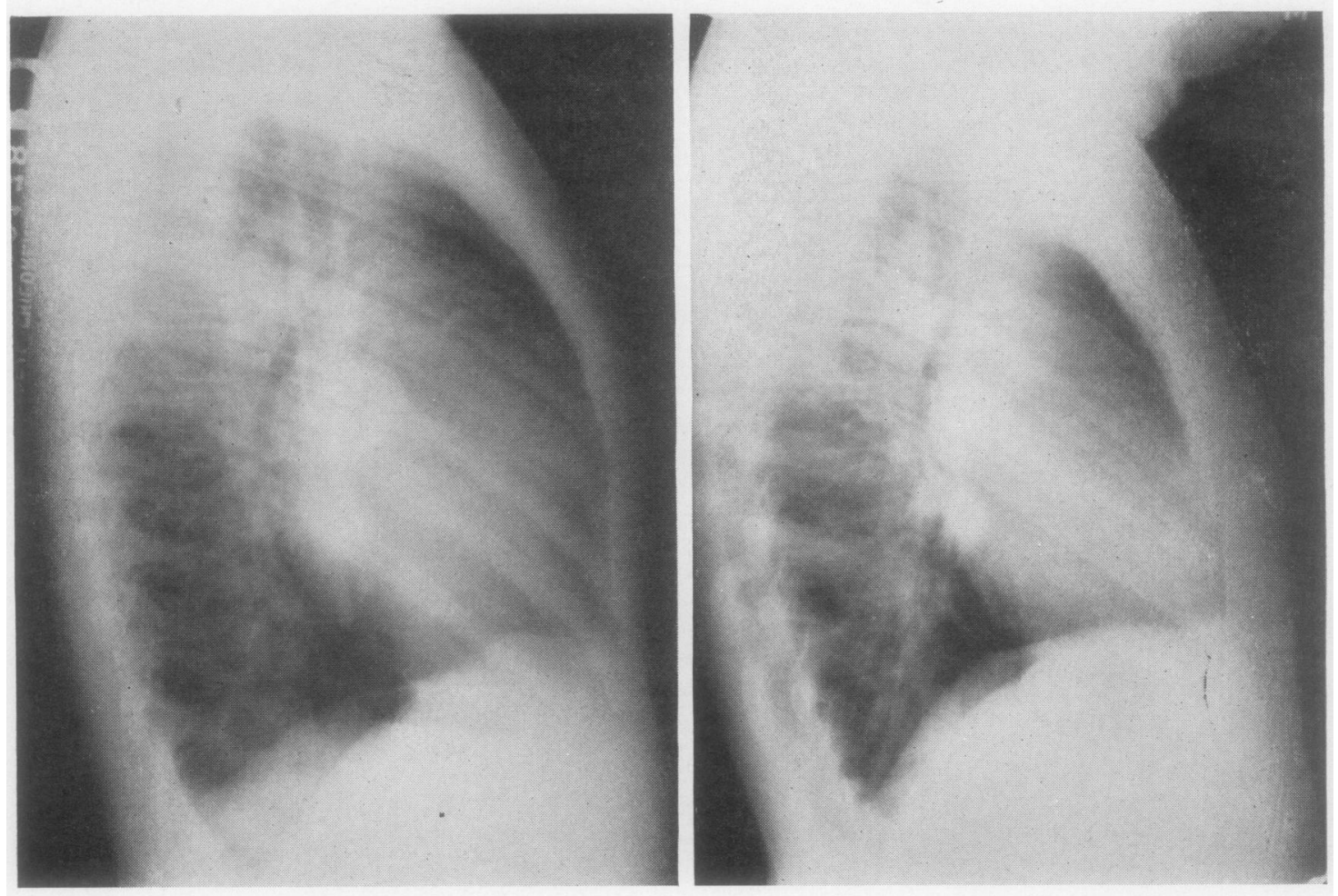

(b)
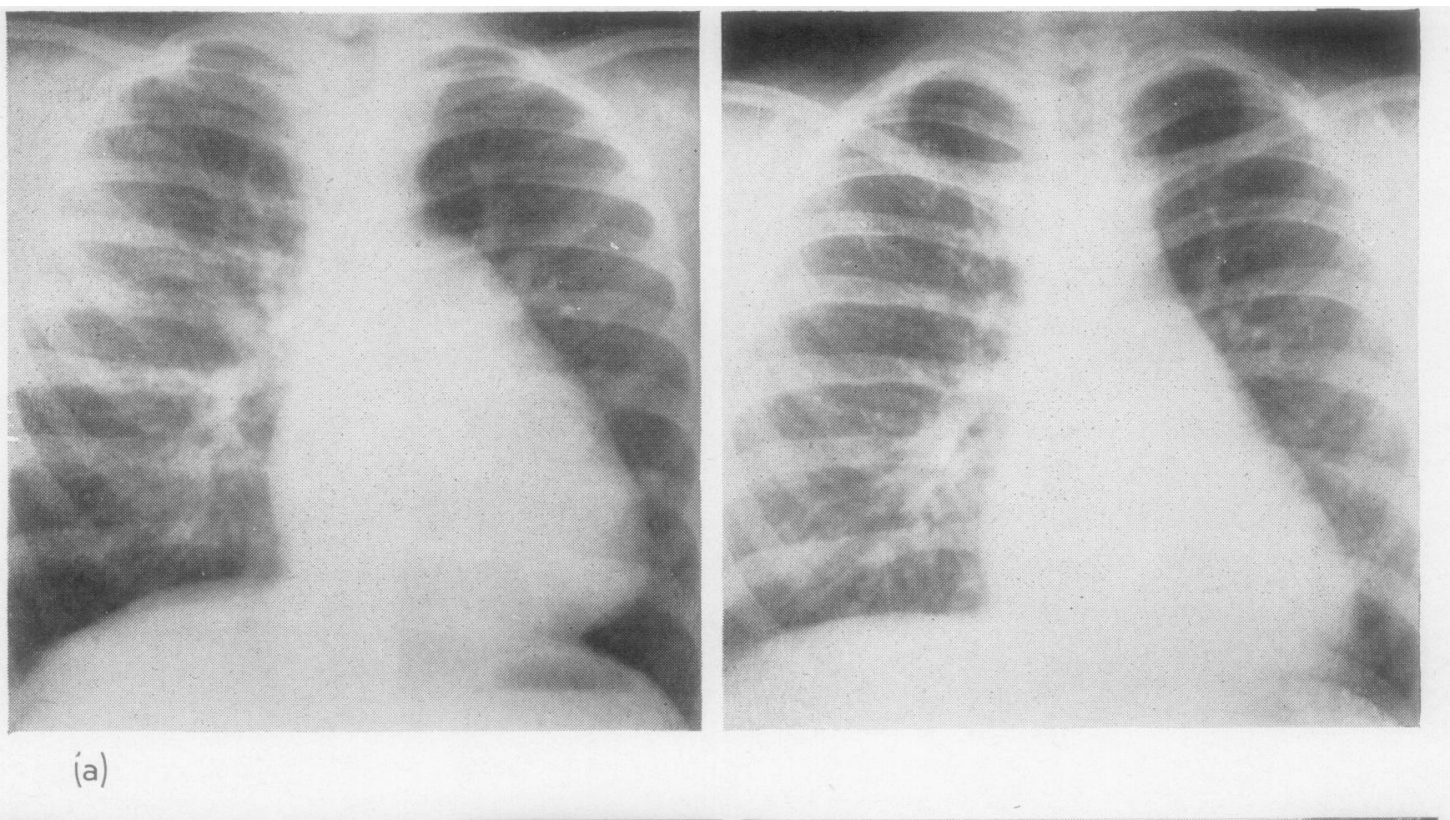

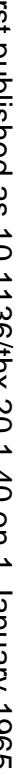

FIG. 2. Pre-operative (left) and post-operative (right) radiographs of a 9-year-old girl who has no residual mitral insufficiency after repair of a partial cushion defect. 

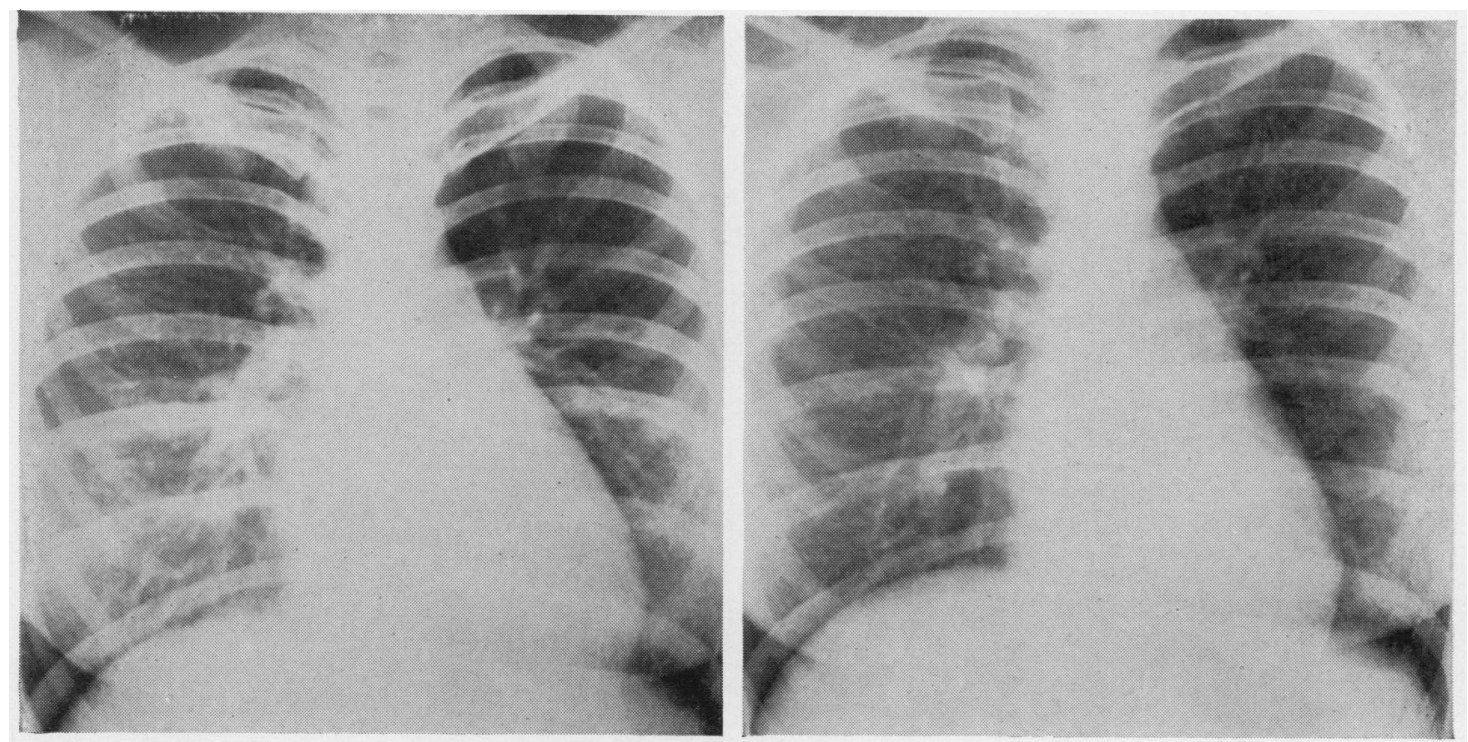

(a)
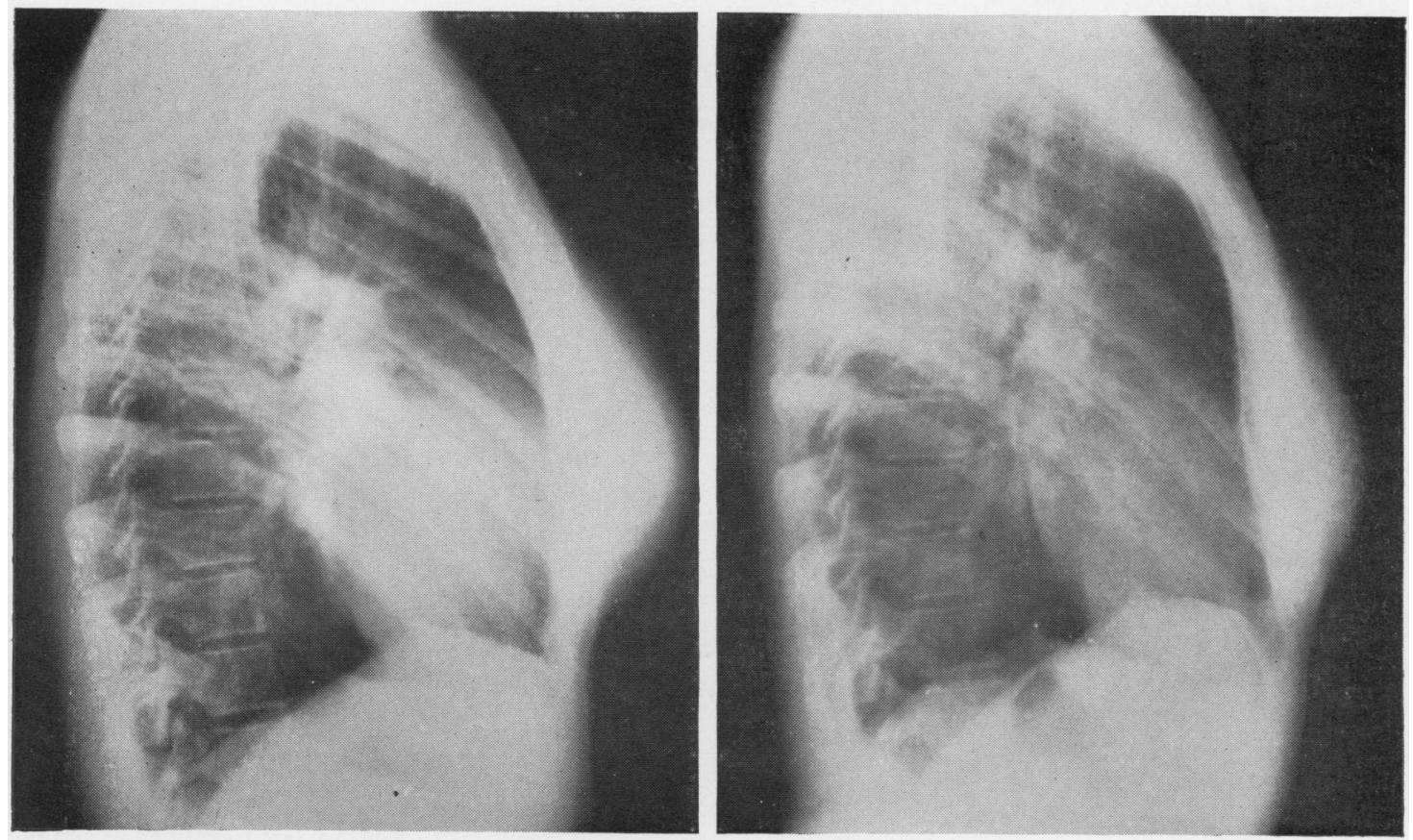

(b)

FIG. 3. Pre-operative (left) and post-operative (right) radiographs of a 16-year-old girl who has clinically insignificant mitral insufficiency after repair of a partial cushion defect. 

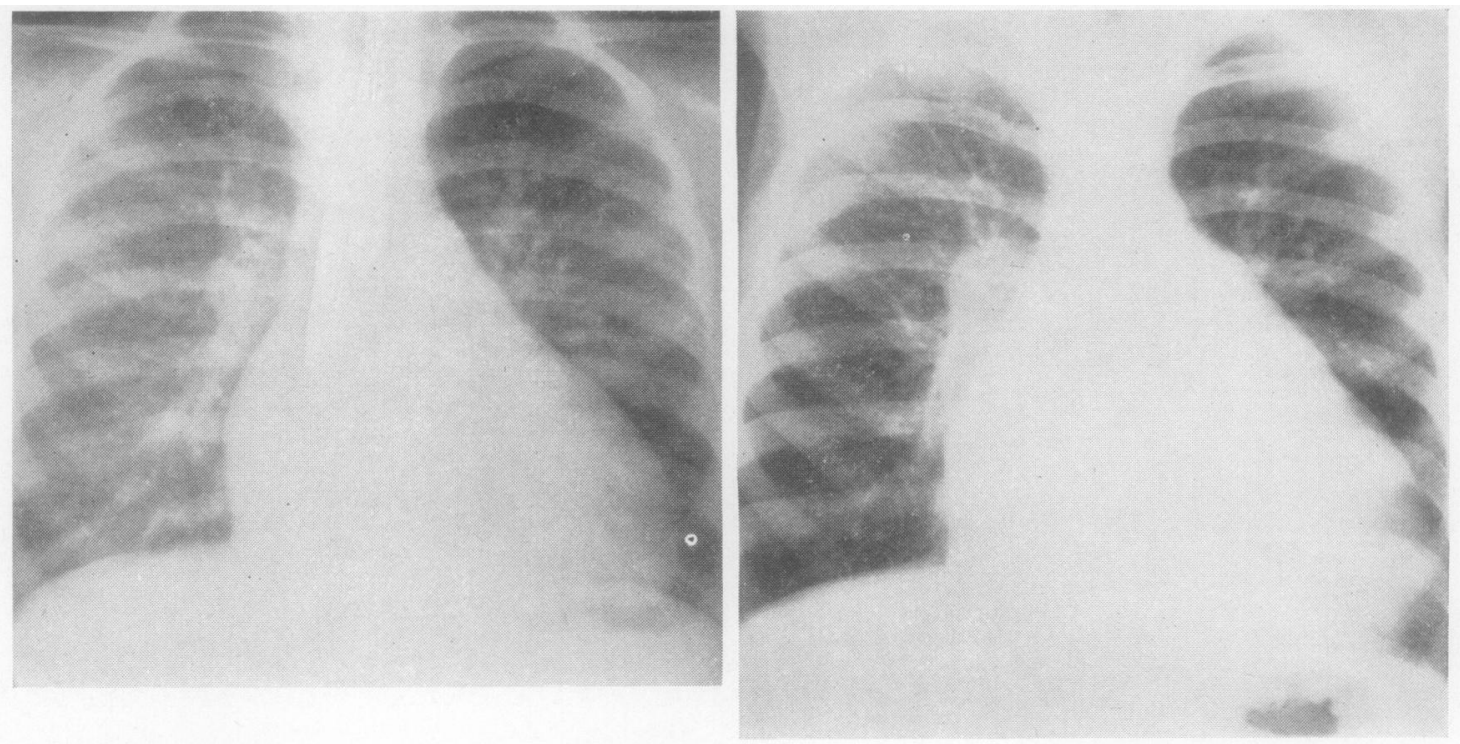

(a)
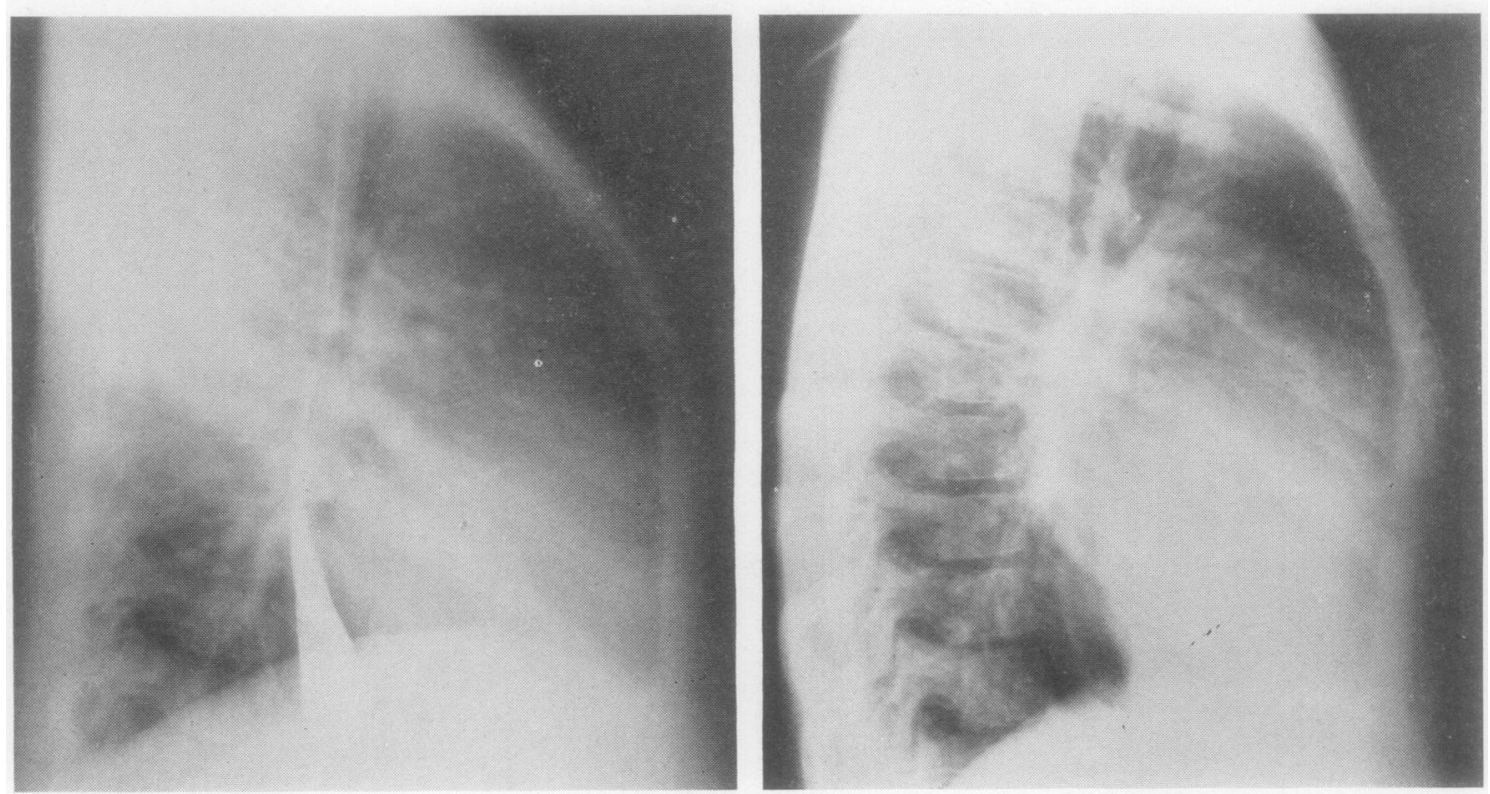

(b)

FIG. 4. Pre-operative (left) and post-operative (right) radiographs of a 6-year-old boy who has significant mitral insufficiency after repair of a partial cushion defect. 
cant. The remaining two patients have significant mitral insufficiency. None of the eight patients without mitral insufficiency have symptoms, nor do they have a pansystolic murmur (Table II). The heart size is markedly to moderately reduced in seven of the eight, and there is no left atrial enlargement in any of these patients. Since the pulmonary flow is also reduced, we consider that they have been totally corrected at operation.

TABLE II

PARTIAL ENDOCARDIAL CUSHION DEFECTS : POSTOPERATIVE RESULTS IN 8 PATIENTS WITHOUT MITRAL INSUFFICIENCY

\begin{tabular}{|c|c|c|}
\hline $\begin{array}{l}\text { Symptoms .. . } \\
\text { Pansystolic murmur at apex } . . \\
\text { Heart size moderately to markedly } \\
\text { (radiograph).. } \\
\text { Left atrial enlargement (radiograph) }\end{array}$ & $\begin{array}{c}\ddot{c} \\
\ddot{\operatorname{ced}} \\
\cdots \\
\cdots\end{array}$ & 0 \\
\hline
\end{tabular}

Typical is the case of a 9-year-old girl who was operated upon in 1960. At the time she was asymptomatic. In addition to the physical signs of the left to right shunt there was a prominent apical pansystolic murmur. At operation the cleft in the mural leaflet was repaired with two interrupted sutures. A teflon felt patch was sutured into the defect. In addition the patent foramen ovale was closed in such a way as to direct the blood from an anomalous pulmonary vein from the right lung into the left atrium. When examined three years after operation she was completely asymptomatic and no heart murmurs were audible. Radiographically (Fig. 2) the heart size has decreased moderately, and the pulmonary flow is normal. There is no enlargement of the left atrium.

In seven patients (Table III) mitral insufficiency, although present, does not appear to be clinically significant. Typical of this group is a 16-year-old

TAB LE III

PARTIAL ENDOCARDIAL CUSHION DEFECTS : POSTOPERATIVE RESULTS IN 7 PATIENTS WITH CLINICALLY INSIGNIFICANT MITRAL INSUFFICIENCY

Symptoms

Pansystolic murmur

Heart size reduced (radio $\cdots$.

Left atrial enlargement (radiograph)

0

7

atrial enlargement (radiograph) ..

girl who had definite exercise limitation before her operation four years ago. She had to give up sports in high school and was dyspnoeic on climbing one flight of stairs. Examination revealed a grade 3 out of 6 pansystolic murmur in addition to the signs of the left to right shunt at the atrial level. At operation a cleft in the aortic leaflet of the mitral valve was closed with interrupted sutures. A patch of teflon felt was placed in the defect. Heart block was produced on tying down one of the sutures ; this suture was immediately removed and the heart block soon disappeared. When examined three years after operation, she was asymptomatic and leading an active life. There was satisfactory reduction of heart size (Fig. 3) and the vascular markings were reduced. There was no enlargement of the left atrium. A pansystolic grade 2 out of 6 murmur was audible at the apex.

Two patients with residual mitral insufficiency are symptomatic. In one, the symptoms are a residual limitation of activity, and tiredness on exertion. This boy has a grade 4 out of 6 pansystolic murmur at the apex, although his heart size is slightly reduced radiographically. The other boy was 6 years old when he was operated upon three and a half years ago. At that time he tired easily and had significant exercise limitation. The pansystolic murmur was prominent. At operation the cleft in the mitral valve was closed with four sutures of silk, and the defect was closed with a teflon felt patch. At the present time he is again considerably limited in his activities, and there is a blowing grade 4 out of 6 pansystolic apical murmur. The radiographs (Fig. 4) show pulmonary venous congestion, although there is a reduction in pulmonary blood flow, and the lateral radiograph shows enlargement of the left atrium.

\section{DISCUSSION}

In our hands at least, the mitral insufficiency, which forms a prominent part of either the complete or the partial forms of endocardial cushion defects, cannot always be surgically eliminated. Whether this is due to abnormal chordae (Edwards, 1960), which we have not recognized, or to dilatation of the mitral ring, or to deformity of the mitral valve produced by suturing the two margins of the cleft aortic leaflet of that valve together, is uncertain. We have re-operated on one child who had residual mitral insufficiency after repair of a complete cushion defect. We considered it necessary to reduce the size of the mitral annulus as well as adding additional sutures to the repair of the cleft leaflet. This operation was carried out through the left atrium and no accessory chordae were discovered. Certainly the residual mitral insufficiency is insignificant in most patients who have had a repair of an ostium primum atrial septal defect. Only prolonged post-operative follow-up examinations will indicate whether this mitral insufficiency will ever become significant. Parenthetically it might be added that this group of patients constitutes an interesting series for 
comparison with children who have rheumatic mitral insufficiency. The latter have myocardial damage in addition to the valvular lesion, and their later downhill course has been repeatedly demonstrated. It is to be hoped that the patients who now have clinically insignificant mitral insufficiency after repair of the cushion defect will not deteriorate further. Those patients with significant mitral insufficiency will obviously have to be re-operated upon.

\section{SUMMARY AND CONCLUSIONS}

Eighteen patients with partial endocardial cushion defects (ostium primum atrial septal defect) were operated upon without mortality. One patient was omitted from the follow-up evaluation because the operation was too recent. Of the 17 patients followed, eight have no mitral insufficiency and nine have some mitral insufficiency which is clinically significant in two patients.
We are indebted to Drs. A. L. Johnson, J. E. Gibbons, and W. Jegier for the cardiological assessment of these patients.

\section{REFERENCES}

Cooley, J. C., Kirklin, J. W., and Harshbarger, H. G. (1957). The surgical treatment of persistent common atrioventricular canal. Surgery, 41, 147.

Crafoord, C., and Senning, A. (1960). Persistent atrioventricular canal. Surgical experiences. Amer. J. Cardiol., 6, 618 .

Dubost, C., and Blondeau, P. (1960). The surgical repair of persistent atrioventricular canal; results in 26 operative cases. Ibid., 6, 611.

Edwards, J. E. (1960). The problem of mitral insufficiency caused by accessory chordae tendineae in persistent common atrioventriaccessory chordae tendineae in persist
cular canal. Proc. Mayo Clin., 35, 299.

Ellis, F. H., McGoon, D. C., and Kirklin, J. W. (1960). Surgical management of persistent common atrioventricular canal. Amer. J. Cardiol., 6, 598.

Gerbode, F., Johnston, J. B., Robinson, S., Harkins, G. A., and Osborn, J. J. (1961), Endocardial cushion defects : diagnosis and technique of surgical repair. Surgery, $49,69$.

Maloney, J. V., Marable, S. A., and Mulder, D. G. (1962). The surgical treatment of common atrioventricular canal. J. thorac. cardiovasc. Surg., 43, 84.

McGoon, D. C., DuShane, J. W., and Kirklin, J. W. (1959). The surgical treatment of endocardial cushion defects. Surgery, 46, 185.

Scott, L. P., Hauck, A. J., Nadas, A. S., and Gross, R. E. (1962). Endocardial cushion defect. Preoperative and postoperative survey. Circulation, 26, 218. 